\title{
The Effect of Computer Games on Students' Critical Thinking Disposition and Educational Achievement
}

\author{
Mohammad Seifi \\ Faculty of Literature and Human Sciences, Arak University \\ PO box 38156 - 879, Arak, Iran \\ E-mail: m-seifi@araku.ac.ir \\ Zahra Derikvandi \\ Faculty of Literature and Human Sciences, Arak University \\ PO box 38156 - 879, Arak, Iran \\ E-mail: zderikvandi68@gmail.com \\ Saeed Moosavipour \\ Faculty of Literature and Human Sciences, Arak University \\ PO box 38156 - 879, Arak, Iran \\ E-mail: s-moosavipour@araku.ac.ir \\ Rouhollah Khodabandelou (Corresponding author) \\ Faculty of Education and Languages, HELP University \\ Wisma HELP, Jalan Dungun, Kuala Lumpur, 50490, Malaysia \\ E-mail: r.khodabandeh@help.edu.my
}

Received: 17-08- 2015

doi:10.7575/aiac.ijels.v.3n.4p.36
Accepted: 01-10-2015

URL: http://dx.doi.org/10.7575/aiac.ijels.v.3n.4p.36

Published: 31-10-2015

\begin{abstract}
The main aim of this research was to investigate the effect of computer games on student' critical thinking disposition and educational achievement. The research method was descriptive, and its type was casual-comparative. The sample included 270 female high school students in Andimeshk town selected by multistage cluster method. Ricketts questionnaire was used to test critical thinking and the researcher made questionnaires were used to test computer games. T-test and one-way ANOVA were employed to analysis of the data. The findings of the study showed that playing computer games has no significant effect on critical thinking, however, there were a significant effect of playing computer games on students' educational achievement $(\mathrm{P}<0 / 05)$. Furthermore, the results showed that the type of computer game has no significant effect on students' disposition to critical thinking and their educational achievement.
\end{abstract}

Keywords: Computer games, disposition to critical thinking, educational achievement, secondary students

\section{Introduction}

As the technology improvement cases the possibility of many things, it has made some wanted and unwanted significant changes in peoples' daily life. In the ground of modern cultural and industrial competition, the computer games as a new phenomenon has a massive grow in a short time. Moreover, it has attracted the interest of many countries and governors. This cultural arm as a quiet and effective media has effected all aspects of our life. Children, teenagers and adults are attracted to them interestingly and receive their evident and hidden messages (Mehrabifar, Mortazavi \& Lesani, 2012). Because of the fascinated attraction of these games for children and teenagers, they spend a lot of time playing games, in fact students spend their mental and nervure energy on these games to finish the games with tired eyes and mind (Motahari, 2005). Since the computer games have a lot of fans among children and teenagers, these anxieties are more intense and they are based on two factors: the first factor is related to the amount of time that children spend on these games and the second one is related to the nature of the game. So, students whom are potentially regarded as injurious charm full, when children and teenagers ignore the other educational and social activities and spend their free time on these games. In this case the most important concern is that doing computer games take (waste) the time of other activities such as school activities, free study or exercise (Durkin \& Barber, 2002).

The type of effect that these games may have on students always have been the big concern of their parents, educators. Besides, the results of the present studies in this area are not the same. One of the big concerns of parents and educators is the positive or negative effects of educational games on educational achievement. While some studies (Yang \& 
Chang, 2013) show the positive effect of computer games on the educational achievement, the findings of other studies report the contrary results (Papastergiou, 2009). However, there are some studies which do not report any significant difference between the mean score of sample and control groups' educational achievement. For example, Yee et al (2009) conducted a study under name "From one student's engagement with computer games and its effect on their educational achievement in Malaysian school", considered the relationship between computer games and students' educational achievement and concluded that there is no significant difference between computer games and students' educational achievement. Furthermore, Mehrabifar et al (2012) organized a research named "Reviewing the types of computer games and the time spent on them and their relationship with the students' educational achievement in Kerman school". The research findings revealed that the effects of games on the students' educational achievement mostly depends on the type of games. Nevertheless, there was not a significant relationship between the duration of plying games and the educational achievement. Fans of computer games don't limit their discussions of educational achievement. From this kind of people point of view, the type of games make children probe and it causes to improve the level of their memory and their concentration. When these games are seriously used in educational and learning purposes, the interaction in a game and learning takes place together. In fact most of the games which are entertainment in nature, create a think in the students mind and despite of this imagination that computer games are entertainment and there are no mental and educational activity, it should be said that playing game, players learn many things in a virtual environment and because of the problem solving process in these games, the player's mental activities will be increased. So, these activities will be transferred to the real world (Hosseni, 2012). In most of the games, children select different options, command, lead and do subtle and deep search in their play environment (Zare \& Jahanara, 2013). Therefore, such activities have made the games as a powerful cognitive learning source and have created different skills such as critical thinking and problem solving (Gunter, 2008).

The term critical thinking is used in literature particularly in the field of education. It has been defined by Dewey (1933) as "active persistent and careful consideration of a belief or supposed form of knowledge in light of the grounds that support it, and the further conclusions to which it tends" ( $p, 118)$. Critical thinking disposition however is defined as "consistent internal motivation to engage problems and make decisions through the use of critical thinking" (Facione et al., 1995). Review of literature (Bell \& Loon, 2015) indicates that critical thinking disposition is attitudinal and can be developed. However, there is less evidence to show the development of critical thinking disposition development through educational games.

Since, the computer games have challenging and based on problem solving environment, they stimulate the students creativity, the effects of computer games on problem solving skills and creativity has been prove by researchers (Roe $\&$ Muijs, 2000). In order to win and get to desired result in computer games, players should recognize the probable challenges and think about them and afford to solve them (Khalife \& Ebrahimi, 2012). For example, Saberi (2013) organized a research on the effects of computer games on male students' creativity in guidance school. The results revealed that there was a significant difference $(\mathrm{P}<0 / 05)$ between experimental and control groups. Correspondingly, in other research Khalife and Ebrahimi (2012) conducted a study to find the relationship between student creativity and educational achievement in female high school. The findings showed that there was a significant difference between creativity and educational achievement regarding the experience and the time spent on computer games.

Nevertheless, the most important issue regarding instructional game research is considering the effect of games on players' critical thinking, since growing critical thinking has been identified as one of the main aims of education. (Ebrahim Dinani, Noruzi \& Khangarkhani, 2008). The critical thinking is a kind of intellectual and reflective thinking that focuses on doing things or believe (Ennis, 1985). One of the most important aims of critical education is preparing critical citizens to have on active partnership in society.

Considerable amount of researches on the effects of computer games on players' critical thinking area, report its positive effect. From Garalee's (2011) point of view, serious and purposeful games can help students to improve useful skills such as critical thinking. These games from the beginning of construction have been faced with some obstacles, probabilities, reasonable trajectory, success, prize, etc. For this reason, games have become one of the most effective ways to create critical thinking. In a critical thinking research which has been conducted by Ru-Song (2008), to investigate the effect of online group games on writing ability and critical thinking skills. The finding showed that online group games help university students to increase and improve their writing ability. The researches which have been conducted in Iran confirmed the positive effect of these types of games on critical thinking. For example, Vafa (2013) organized a research on the effects of computer games on critical thinking in high school students .The results of the study confirmed the research hypothesis which was computer games have positive effect on students' critical thinking.

However, there are some researches which have not reported any significant relationship between games and students' critical thinking. For example, Mahbubi (2010) prepared a research to consider the relationship between the amount of different digital games using and the level of critical thinking among the high school students. The results of this research revealed that there is no relationship between six groups of games (action, puzzle, strategic, educational, adventure, simulation) and the level of critical thinking.

Regarding the various and sometimes contradictory reports in relation to the effects of computer games on critical thinking and educational achievement and also regarding the importance of these two variables, it seems that it is 
necessary to do more researches specially regarding with types of games. Therefore, the purpose of the current study was to investigate the effects of using computer games on the disposition to critical thinking and educational achievement of female high school students in Andimeshk town, Iran. Based on the main purpose, the following objectives were addressed:

1. To examine the effect of computer games on students' critical thinking disposition,

2. To examine the effect of computer games on students' educational achievement,

3. To identify effects of different computer games on students' critical thinking, and

4. To identify effects of different computer games on students' educational achievement.

In order to meet these objectives, the researches postulated the following hypotheses:

1. Computer games significantly affect students' critical thinking disposition.

2. Computer games significantly affect students' educational achievement.

3. Different types of computer games have significantly different effects on students' critical thinking disposition.

4. Different types of computer games have significantly different effects on students' educational achievement.

\section{Methodology}

This research is descriptive in nature and its type is cause-comparative. The data were collected from first grade female high school students $(\mathrm{n}=900)$ in Andimeshk, Iran, in 2012. Based on Krejcie and Morgan (1970) table, 270 samples were selected. Multistage clustering was used as the sampling method. Five schools were selected randomly from 15 female high schools, and in the next step 2 classes were selected randomly to fill the questionnaire.

\subsection{Instrumentation}

One of the research instruments was a researcher-developed questionnaire. Some of the items of the questionnaire related to the features of population recognition, while others concerned the quantity and quality of computer games used by the students. The questionnaire also elicited data from the students regarding the duration of their playing computer games (in hours per week) and the kinds of their favorite games.

In order to measure the students' critical thinking, California Critical Thinking Disposition Inventory (CCTDI) standard questionnaire, which was designed and validated by Ricketts (2003) was used. Ricketts tried to prepare a shorter more effective and more important scale. The disposition to critical thinking questionnaire has been made based on Fasion (1990) critical thinking scale. The subject in a five grade Likert scale (from I severely disagree=1, to I strongly agree= 5) determined the amount of his/her agreement with one of the items. In 2, 12, 15, 19, 23, 30, 32, 33 items, the scoring was in an inverted manner. To standardize questionnaire Ricketts (2003) performed it on 60 second grade agriculture students. The reliability coefficient of this research subscales was reported as follows: The creativity subscales $=75 \%$, the boast subscale $=57 \%$ and the commitment subscale $=86 \%$ (Amirpour, 2012). The internal reliability coefficient of the instrument in the present study was 0.90 .

The data on the students' educational achievement were collected by adding a section to the questionnaire in which they would state their CGPA. In case of missing data, the student's academic profile was reviewed.

\subsection{Data Collection Procedure}

The questionnaires were distributed among the selected students in class and after a preliminary explanation. They answered the questions in the questionnaire. After collecting and coding the questionnaires, the data were analyzed using the IBM SPSS (version 21).

Both descriptive and inferential statistics were applied. At descriptive statistics level the frequency, mean and standard deviation were reported. At the inferential statistics level the one-way ANOVA and T-test were used for independent groups.

\section{Findings}

Before reporting the results of testing the hypotheses, some useful descriptive information is presented in this section. Table 1 presents the frequency and percentage of students who had computer games at home:

Table 1. Descriptive statistics results of students who had computer games at home

\begin{tabular}{lcc}
\hline Response & $\mathrm{N}$ & $\%$ \\
\hline YES & 195 & 72.2 \\
NO & 75 & 27.8 \\
Total & 270 & 100 \\
\hline
\end{tabular}

As it can be seen in Table 1 most of the subjects (72.2\%) stated that they had computer games at home. 
Table 2. Descriptive statistics results of the type of computer games

\begin{tabular}{lcc}
\hline Game type & $\mathrm{N}$ & $\%$ \\
\hline Mental - educational & 70 & 25.9 \\
Fighting (Military) & 35 & 13.0 \\
Adventurous & 98 & 36.3 \\
Athletic - epical & 18 & 6.7 \\
Non - play & 49 & 18.1 \\
Total & 270 & 100 \\
\hline
\end{tabular}

Table 2 shows the frequency of computer games used by students. The table shows the percentage was: adventurous $36.3 \%$, intellectual-instructional $25.9 \%$, fighting $13.0 \%$ and athletic-epical $6.7 \%$.

\subsection{Hypothesis testing}

The first null hypothesis of this study was 'Computer games do not significantly affect students' critical thinking disposition'.

Table 3. Effect of playing computer games on students' critical thinking disposition

\begin{tabular}{clllllll}
\hline Variable & & $\mathrm{N}$ & Mean & Std. & $\mathrm{t}$ & $\mathrm{df}$ & Sig.(2-tailed) \\
\hline Critical & Play game & 221 & 120.86 & 12.73 & \multirow{2}{*}{1.72} & \multirow{2}{*}{268} & .086 \\
thinking & Non- Play game & 49 & 117.40 & 12.55 & & & \\
\hline
\end{tabular}

As it can be seen, in order to calculate the students' critical thinking disposition in playing and non-playing groups, the independent t-test was used. Based on the summary of the results in Table 3, we failed to reject the null hypothesis $(t(268)=1.72, p=0.08)$. Thus, it can be concluded that playing computer games does not have any effect on students' critical thinking disposition in any of the groups.

The second null hypothesis to be tested was 'Computer games do not significantly affect students' educational achievement'.

Table 4. Effect of playing computer games on students' educational achievement

\begin{tabular}{llllllll}
\hline Variable & & $\mathrm{N}$ & Mean & Std. & $\mathrm{t}$ & $\mathrm{df}$ & Sig.(2-tailed \\
\hline Educational & Play game & 221 & 18.97 & 1.20 & \multirow{2}{*}{4.328} & 268 & .000 \\
Achievement & Non- Play game & 49 & 17.95 & 1.55 & & & \\
\hline
\end{tabular}

As it can be seen, in order to calculate the educational achievement in playing and non-playing groups, the independent t-test was used. Based on the summary of the results in Table 4, the null hypothesis is rejected, $t(268)=4.32, p=.000$. So, it can be concluded that playing computer games has a significant effect on students' educational achievement.

The next null hypothesis was 'Different type of computer games have no significantly different effects on students' critical thinking disposition'.

Table 5. One-way ANOVA results of the effect of game types on students' critical thinking disposition

\begin{tabular}{lccccc}
\hline & SS & df & MS & F & Sig \\
Between Groups & 216.376 & 3 & 72.125 & & .44 \\
Within Groups & 35455.55 & 217 & 163.39 & & .72 \\
Total & 35671.92 & 220 & & & \\
\hline
\end{tabular}

Based on the summery of the results in Table 5, the null hypothesis is confirmed and the research hypothesis is rejected $(F(3,217)=0.44, p=0.72)$. So, it can be concluded that regarding the type of the game, there is no significant difference between students' critical thinking disposition mean.

The final hypothesis was 'Different type of computer games have significantly different effects on students' educational achievement'. 


\begin{tabular}{llcllr}
\multicolumn{1}{l}{ Table 6. One-way ANOVA results of the effect of game types on students’ educational achievement } \\
\hline SS & df & MS & F & Sig \\
\hline Between Groups & 5.036 & 3 & 1.688 & & 1.17 \\
Within Groups & 312.057 & 217 & 1.438 & \\
Total & 317.120 & 220 & & \\
\hline
\end{tabular}

Based on the summery of the results in Table 6 , we failed to reject the null hypothesis $(F(3,217)=1.17, p=0.32)$. So, it can be concluded that different types of computer games do not result in significant differences between students' educational achievement means.

\section{Discussion and Conclusion}

This research was formed with the general aim of considering the effects of using computer games on the students' critical thinking disposition and educational achievement at a female high school Andimeshk, Iran.

The finding of the research showed that playing computer games has a positive significant effect on students' educational achievement, but has no significant effect on critical thinking disposition. This finding is in line with the studies of Mahbubi (2010), Young et al (2013). However, the results of the current study was not in line with some other studies such as Yee et al (2009), Mehrabi et al. (2012), and Ru-Sung (2008). Likewise, the results showed that different types of computer games was no significant effects on students' critical thinking and their educational achievement.

Since there was a positive effect of computer games on students' educational achievement, it can be concluded that parents to monitor and control their children's use of computers and establish rules for computer usage. Parents should plan the use of computers so that the descendants do not stay away of their original mandate which is education and learning. Based on the results of the current study it can be concluded that computer games can help to improve students' learning. However, considerable amount of research is necessary to confirm this claim in which parents' control is the independent variable.

Some of the games have been effective in increasing the level of a person's critical thinking, since people who are faced with ambiguous situations, so they have caused to improve the cognitive skills and have made him/her think and be creative. As a result the educational achievement is improved. The results that indicated the negative effects of computer games on educational achievement can be interpreted as the possibility inappropriate or spend a long time playing computer games, so these factors had made their academic failure.

The lack of influence of the games on students' critical thinking which was contrasted with the results of some studies, can be interpreted that as the participants in this study was from different cultures and they were affected by different training factors. The content and quality of the games were controlled and it is expected to have different results. In addition, it has been confirmed that the effective factors on critical thinking are not the same in the different societies. Among these cultural factors, economic and social situation can be considered as effective factors which have effect on critical thinking.

In the Iranian educational system, traditional learning-teaching methods are used. In fact, in this system the role of student is memorizing the content only. The students are inactive roles in teaching and learning processes. Furthermore, the assessment and evaluation system is formed based on these inactive roles. In such circumstances, the effects of games on the growth of critical thinking, is attracted less attention by parents and teachers or even in educational evaluators.

\section{References}

Amirpour, B. (2012). The relationship between critical thinking and its aspects with happiness and students' social selfrespect. Quarterly of Educational Strategy, 5(3), 1-5.

Bell, R., \& Loon, M. (2015). The impact of critical thinking disposition on learning using business simulations. The International Journal of Management Education. 13, 119-127.

Dewey, J. (1933). How we think. New York: D.C Health \& Co Publishers.

Durkin, K., \& Barber, B. (2002). Not so zoomed: Computer game play and positive adolescent development. Applied Developmental Psychology, 23, 373-392.

Ebrahimi Dinani, A., Noruzi, A., \& Khangarkhani, Z. (2008). A prelude to meaning necessity and application of critical thinking in education. Science Journal, 16(73), 1-30.

Ennis, R.H. (1985). Developing Minds: A resource book for teaching thinking (3rd), Association for Supervision and Curriculum Development. USA.

Facione, P., Giancarlo, C., Facione, N., et al. (1995). The disposition toward critical thinking. Journal of General Education, 44(1), 1-25. 
Garalee, A. (2011). Play to learn: Great projects to try, websites to bookmark, and a world of learning to share with student. Journal Articles, Reports -Descriptive, 120(5), 64-66.

Gunter, B. (2008). The effects of computer and video games on children. (Translate by Seyed Hassan pur Abedi Naeini). Tehran: Javaneh Roshd.

Bai, H., Pen, W., Hirumi, H., \& Kebritichi, M. (2012). Assessing the effectiveness of a 3-D instructional game on improving mathematics achievement and motivation of middle school students. British Journal of Education Technology, 43(6), 993-1003.

Khalife, Gh., \& Ebrahimi Nobandegani, M. (2012). Considering the relationship between creativity and educational achievement with computer games in high school girl students in Ahwaz. Educational journal, 6(1), 171-192.

Krejcie, R. V., \& Morgan, D. W. (1970). Determining sample size for research activities. Educational and Psychological Measurement, 30, 607-610.

Mahbubi, F. (2010). Considering the amount (rate) of using different kinds of digital games and the level of critical thinking among science high school students in Baneh town. Unpublished Master Thesis. Alameh Tabatabaei University, Iran.

Mehrabifar, F., Mortazavi, H., \& Lesani, M. (2012). Reviewing the types of computer games and the time spent on them and their relationship with the students' educational achievement in Kerman school. Research in Curriculum. 2(7), 1-11.

Motahari, M. (2005). Guidelines for educational games selection. Tehran: Alborz

Papastergiou, M. (2009). Digital game-based learning in high school computer science education: impact on educational effectiveness and student motivation. Computers \& Education. 52(1). 1-12.

Ricketts J. C. (2003). Critical thinking skills of FFA leaders. Journal of Southern Agricultural Education Research, 54(1), 21-33.

Roe, K., \& Muijs, D. (2000). Children and computer game: A profile of the heavy user. European Journal of Communication, 13(2), 181-200.

Ru-Song, Ch. (2008). Educational games with blogs: Collaborating to motivate second language undergraduate critical thinking. Online Information Review, 32(5), 557-573.

Saberi, M. (2013). The effect of computer games on Creativity, Retrieved August 26, 2015, from: http://www.ravanagahi.ir

Yang, J. C., \& Chang, H. T. (2013). A Digital Game-Based Mobile Learning System for Energy Education. Global Chinese Journal on Computers in Education, 9(1-2), 87-98.

Young, M. F. et al. (2012). Our princess is in another castle: A review of trends in serious gaming for education. Review of Educational Researches. 82(1), 61-89.

Zare, H., \& Jahanara, A. (2013). The Effect of Computer Games on Information Processing in Young Adults, Thinking and Children, 4(7), 27-49. 